\title{
Determination of irradiated reactor uranium in soil samples in Belarus using ${ }^{236} \mathrm{U}$ as irradiated uranium tracer
}

\author{
Vladislav P. Mironov, ${ }^{a}$ Janna L. Matusevich, ${ }^{a}$ Vladimir P. Kudrjashov, ${ }^{a}$ \\ Sergei F. Boulyga ${ }^{b, c}$ and J. Sabine Becker*c \\ ${ }^{a}$ Institute of Radiobiology, 220141 Minsk, Belarus \\ ${ }^{b}$ Radiation Physics and Chemistry Problems Institute, 220109, Sosny, Minsk, Belarus \\ ${ }^{c}$ Central Department of Analytical Chemistry, Research Center Jülich, D-52425 Jülich, \\ Germany.E-mail: s.becker@fz-juelich.de
}

\author{
Received 2nd August 2002, Accepted 27th August 2002 \\ First published as an Advance Article on the web 18th September 2002
}

\begin{abstract}
This work presents experimental results on the distribution of irradiated reactor uranium from fallout after the accident at Chernobyl Nuclear Power Plant (NPP) in comparison to natural uranium distribution in different soil types. Oxidation processes and vertical migration of irradiated uranium in soils typical of the $30 \mathrm{~km}$ relocation area around Chernobyl NPP were studied using ${ }^{236} \mathrm{U}$ as the tracer for irradiated reactor uranium and inductively coupled plasma mass spectrometry as the analytical method for uranium isotope ratio measurements. Measurements of natural uranium yielded significant variations of its concentration in upper soil layers from $2 \times 10^{-7} \mathrm{~g} \mathrm{~g}^{-1}$ to $3.4 \times 10^{-6} \mathrm{~g} \mathrm{~g}^{-1}$. Concentrations of irradiated uranium in the upper $0-10 \mathrm{~cm}$ soil layers at the investigated sampling sites varied from $5 \times 10^{-12} \mathrm{~g} \mathrm{~g}^{-1}$ to $2 \times 10^{-6} \mathrm{~g} \mathrm{~g}^{-1}$ depending on the distance from Chernobyl NPP. In the majority of investigated soil profiles $78 \%$ to $97 \%$ of irradiated "Chernobyl" uranium is still contained in the upper $0-10 \mathrm{~cm}$ soil layers. The physical and chemical characteristics of the soil do not have any significant influence on processes of fuel particle destruction. Results obtained using carbonate leaching of ${ }^{236} \mathrm{U}$ confirmed that more than $60 \%$ of irradiated "Chernobyl" uranium is still in a tetravalent form, i.e. it is included in the fuel matrix (non-oxidized fuel $\mathrm{UO}_{2}$ ). The average value of the destruction rate of fuel particles determined for the Western radioactive trace $\left(k=0.030 \pm 0.005 \mathrm{yr}^{-1}\right)$ and for the Northern radioactive trace $\left(k=0.035 \pm 0.009 \mathrm{yr}^{-1}\right)$ coincide within experimental errors. Use of leaching of fission products in comparison to leaching of uranium for study of the destruction rate of fuel particles yielded poor coincidence due to the fact that use of fission products does not take into account differences in the chemical properties of fission products and fuel matrix (uranium).
\end{abstract}

\section{Introduction}

The accident at Chernobyl Nuclear Power Plant (NPP) resulted in environmental contamination with particles of irradiated reactor fuel consisting of uranium dioxide with dimensions ranging from less than one micrometer up to several tens of micrometers. These particles contained actinides and fission products $^{1}$ with a specific activity of up to $10^{8} \mathrm{~Bq} \mathrm{~g}^{-1}$. In the primary nuclear fallout after the Chernobyl NPP accident the most dangerous radionuclides of actinides (such as ${ }^{242} \mathrm{Cm}$, ${ }^{244} \mathrm{Cm},{ }^{238} \mathrm{Pu},{ }^{239} \mathrm{Pu},{ }^{240} \mathrm{Pu},{ }^{241} \mathrm{Am}$ etc. ) were bound in relatively chemically inert fuel particles. Therefore, the behavior of radionuclides in the environment was determined by the migration of fuel particles, but it did not depend on the chemical properties of actinides. However, under the effect of active soil components, as a result of nuclear decay and oxidation of tetravalent uranium, fuel particles are destroyed, which leads to an increase of fine particle fraction. ${ }^{2}$ As a result the integral surface square of newly formed fine particles increases raising the leaching rate of fission products from the fuel particles. The mobile (or soluble) fraction of radionuclides increases with time and the radionuclides become more accessible for plants, animals and humans. In addition, increasing the respiratory fraction (fine particle fraction) in the nearground air results in an increasing irradiation dose caused by inhaled actinides. Therefore, study of the migration of fuel particles in soils, the degree of their destruction and leaching dynamics of actinides under different natural effects is important for forecasting the behavior of radioactive fallout in contaminated regions.
According to a previous study ${ }^{3}$ the level of surface soil contamination with "Chernobyl" irradiated uranium in relocation areas in Belarus corresponds approximately to the concentration range of natural uranium $\left(1 \times 10^{-7} \mathrm{~g} \mathrm{~g}^{-1}\right.$ to $\left.2 \times 10^{-6} \mathrm{~g} \mathrm{~g}^{-1}\right)$. Calculations of isotope production in irradiated uranium of the Chernobyl reactor showed that ${ }^{235} \mathrm{U} /{ }^{238} \mathrm{U}$ ratio might vary from $0.0067^{4}$ to $0.0084,,^{5}$ i.e. it is close to the natural abundance ratio of ${ }^{235} \mathrm{U} /{ }^{238} \mathrm{U}(0.00725)$. This fact makes accurate determination of irradiated "Chernobyl" uranium in contaminated soil samples by measuring the ${ }^{235} \mathrm{U} /{ }^{238} \mathrm{U}$ isotope ratio difficult. According to a previous study, ${ }^{6}$ even high-precision multiple ion collector ICP-MS only provided satisfactory results for determination of the nuclear uranium fraction in a nuclear/natural uranium mixture in soil down to $2 \%$. During reactor operation ${ }^{236} \mathrm{U}\left(T_{1 / 2}=2.342 \times 10^{7} \mathrm{yr}\right)$ is produced via ${ }^{235} \mathrm{U}(\mathrm{n}, \gamma){ }^{236} \mathrm{U}$ reaction with a cross section of $95 \mathrm{~b}$ (barns) for thermal neutrons ( $v s$. fission cross section of $586 \mathrm{~b}$ ). At the moment of the accident in Chernobyl the mass ratio ${ }^{236} \mathrm{U} /{ }^{238} \mathrm{U}$ in irradiated reactor fuel was about $(1.4-2.4) \times$ $10^{-3} \mathrm{~g} \mathrm{~g}^{-1} .^{7}$ In naturally occurring uranium, the ${ }^{235} \mathrm{U}(\mathrm{n}, \gamma)$ ${ }^{236} \mathrm{U}$ reaction is produced by neutrons generated by cosmic irradiation, spontaneous fission or $(\alpha, n)$ reaction on light nuclei ${ }^{8}$ and the ${ }^{236} \mathrm{U} /{ }^{238} \mathrm{U}$ isotope ratio is expected to be about $10^{-14}$ in the environment. ${ }^{9}$ The ${ }^{236} \mathrm{U} /{ }^{238} \mathrm{U}$ ratios in natural uranium ores range from $1.2 \times 10^{-11}$ to $5.6 \times 10^{-10}$ due to higher neutron fluxes presented there. ${ }^{9-12}$ Due to this difference of ${ }^{236} \mathrm{U}$ concentration in natural uranium and irradiated reactor uranium this isotope can be useful as a "fingerprint" for the presence of "Chernobyl" uranium in the environment.

Obviously $\alpha$-spectrometry allows the determination of the 
${ }^{236} \mathrm{U} /{ }^{238} \mathrm{U}$ isotopic ratio down to $2.6 \times 10^{-5}$ with a relative uncertainty of about $10 \%,{ }^{13}$ but this method is not sensitive enough for the determination of long-lived ${ }^{236} U$ in environmental samples at the ultratrace concentration level. Thermal ionization mass spectrometry (TIMS) $)^{12}$ and accelerator mass spectrometry (AMS) $)^{9-11}$ are well established techniques for uranium isotopic measurements but these methods are expensive and time-consuming. Inductively coupled plasma mass spectrometry (ICP-MS) provides high sensitivity, good accuracy of isotopic measurements and requires a relatively simple sample preparation procedure ${ }^{14}$ and, therefore, ICP-MS is one of the most suitable methods for routine ${ }^{236} \mathrm{U} /{ }^{238} \mathrm{U}$ isotope ratio measurements in environmental samples. ${ }^{6,15-18}$

The aim of the present work was an experimental study of the vertical migration of irradiated "Chernobyl" uranium in soils typical of the $30 \mathrm{~km}$ relocation area around Chernobyl $\mathrm{NPP}$ using ${ }^{236} \mathrm{U}$ as the tracer of irradiated reactor uranium (in further discussion: "irradiated uranium") and ICP-MS as the analytical method for uranium isotope ratio measurements.

\section{Experimental}

\section{Soil samples and sample preparation}

Soil samples were taken in turf-podzol, sand, sand-clay and peat soils in the $30 \mathrm{~km}$ relocation zone of Chernobyl NPP (Fig. 1) in 1998-2000. To our knowledge and according to the official information, sampling points have been undisturbed by technogenic and anthropogenic activities since the moment of the Chernobyl accident. However, an undocumented land use in the first days after the accident could not be excluded in some sampling areas where the population was not relocated immediately after the accident. The relief of the sampling areas and types of soil were typical of the south of Belarus. Soil was collected with a coring device that was specially designed to cut $10 \mathrm{~mm}$ thick soil layers down to a depth of $60 \mathrm{~cm}$.

Collected soil samples were dried at $105 \pm 5{ }^{\circ} \mathrm{C}$, then they were crushed so that the soil should pass a mesh size of $2 \mathrm{~mm}$ and mixed. Every sample was divided into 5 approximately equal parts and specific activity of each part was measured using the radiometer. In the case of a difference in the activities between sample parts of more than $15 \%$, these subsamples were composed and mixed, then the homogenization procedure was repeated. After homogenization, $250 \mathrm{~g}$ of the sample was ashed at $600 \pm 50{ }^{\circ} \mathrm{C}$ for $1 \mathrm{~h}$. Plant roots and vegetation were incinerated separately at $550 \pm 50{ }^{\circ} \mathrm{C}$ for $2 \mathrm{~h}$ and then the ash was mixed with the sample. The ashed soil sample together with the ${ }^{233} \mathrm{U}$ tracer isotope was digested in a mixture of nitric acid and hydrofluoric acid. Uranium was extracted by ion-exchange chromatography using anionite resin AB-17 (Joint Stock Company Azot, Novomoskovsk, Russia) and extraction with diethyl ether. ${ }^{19}$

\section{Standards and reagents}

The isotope standard reference material NBS U-020 (National Bureau of Standards and Technology, Gaithersburg MD, USA) and an isotopic standard solution of uranium (CCLU500 laboratory standard, Nuclear Research Center, Prague, Czech Republic) ${ }^{20}$ were used for the optimization of isotope ratio measurements of uranium. Uranium isotope ratios for the CCLU-500 laboratory standard were established by calibration against the NIST-500 SRM by TIMS $\left({ }^{234} \mathrm{U} /{ }^{238} \mathrm{U}=0.011122\right.$, $\left.{ }^{235} \mathrm{U} /{ }^{238} \mathrm{U}=0.99991,{ }^{236} \mathrm{U} /{ }^{238} \mathrm{U}=0.002789\right)$. The concentration of ${ }^{233} \mathrm{U}$ solution in ${ }^{233} \mathrm{U}$ standard solution was determined using alpha spectrometry and liquid scintillation spectrometry. A uranium solution of natural isotopic composition was prepared as described in a recent paper. ${ }^{15}$ All reagents were diluted with deionized Milli-Q water (18 M $\Omega$ ) obtained from a Millipore Milli-Q-Plus water purifier to the necessary concentrations for determining the isotopic ratios of uranium by ICP-MS. The solutions were acidified to $1 \%$ subboiled $\mathrm{HNO}_{3}$.

\section{Instrumentation of ICP-MS}

A double-focusing sector-field ICP-MS (ELEMENT, Finnigan MAT, Bremen, Germany) was used for uranium isotopic ratio measurements in soil samples. The ICP torch was shielded with a grounded platinum electrode (GuardElectrode ${ }^{\circledR}$, Finnigan MAT). In addition, a quadrupole-based ICP-MS (Platform ICP, Micromass Ltd., Manchester, UK) with gas-filled hexapole collision cell was applied for the uranium isotopic ratio measurements when an abundance sensitivity for the ${ }^{236} \mathrm{U} /{ }^{238} \mathrm{U}$ isotope ratio of better than $5 \times 10^{-6}$ was required. Helium was introduced into the hexapole cell as a buffer gas.

A Microconcentric MicroMist nebulizer (MicroMist AR401F02) attached to a minicyclonic spray chamber was used for

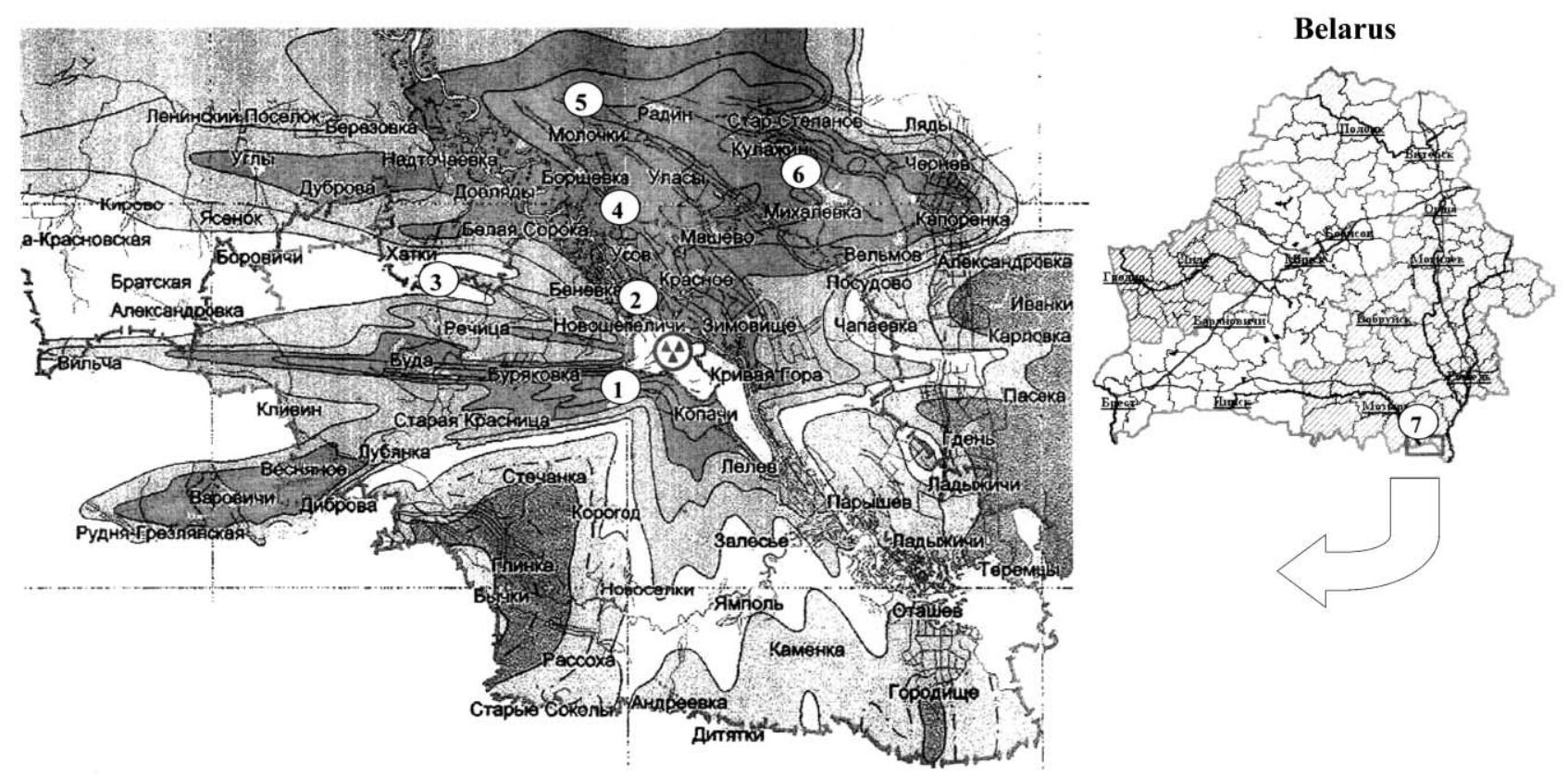

Fig. 1 Map of the sampling sites in the South of Belarus. 
solution introduction in ICP-MS ELEMENT when the expected ${ }^{236} \mathrm{U} /{ }^{238} \mathrm{U}$ isotope ratio was higher than $10^{-4}$. A microconcentric low-flow nebulizer with membrane desolvation (Aridus, CETAC Technologies Inc., Omaha, Nebraska, USA) was used for solution introduction in ICP-MS ELEMENT and Platform when measuring lower isotope ratios. Aqueous solution was introduced into the nebulizer in the continuous flow mode via a peristaltic pump (Perimax 12, Spetec GmbH, Erding, Germany). Further details of the ICP-MS used can be found in ref. 6 and 15-18

\section{Optimization of ICP-MS and measurement procedure}

Optimization of experimental parameters of both the ICP-MS instruments was performed with respect to the maximum ion intensity of ${ }^{238} \mathrm{U}^{+}$and minimum uranium hydride formation rate using uranium solution of natural isotopic composition. As was shown in a previous paper ${ }^{18}$ uranium hydride ion ratio decreased with decreasing $\mathrm{rf}$ power, contrary to the $\mathrm{UO}^{+} / \mathrm{U}^{+}$ ratio. Furthermore, the $\mathrm{UH}^{+} / \mathrm{U}^{+}$ratio was not altered by the shielded plasma torch, which allowed full use to be made of the advantage of higher sensitivity for uranium by the application of the shielded torch in ICP-SFMS. Optimized experimental parameters of the ICP-MS instruments for different solution introduction devices are presented in Table 1. The measured uranium isotopic ratio was corrected taking into account the mass discrimination factor (assuming a linear correlation ${ }^{21,22}$ ) determined experimentally by measuring the CCLU-500 isotope laboratory standard solution as well as hydride rate $\mathrm{UH}^{+} / \mathrm{U}^{+}$ratios and the dead time of the detector of $\mathrm{ICP}_{\mathrm{SFMS}}{ }^{23}$ determined by measuring uranium solution of natural isotope composition and NBS U-020 isotope standard solution. No dead time correction was required in ICP-CCQMS as the 'Daly'-type ion detector operated in analogue mode in this instrument. The combined uncertainty of isotopic ratio measurements was calculated according to EURACHEM/CITAC Guide ${ }^{24}$ taking into account standard deviations of the measured isotope ratio, background at mass $236 \mathrm{u}$ (including instrument background and interfering hydride ions), uncertainty of the mass discrimination factor and uncertainty associated with the isotopic ratios in the standards applied. Details on accuracy and uncertainties of isotope ratio measurements for the two instruments used can be found elsewhere. ${ }^{6,15}$ From the measured ${ }^{235} \mathrm{U} /{ }^{233} \mathrm{U}$ and ${ }^{236} \mathrm{U} /{ }^{233} \mathrm{U}$ and ${ }^{238} \mathrm{U} /{ }^{233} \mathrm{U}$ isotope ratios concentrations of irradiated and natural uranium in soil samples were calculated. The procedure for calculating the irradiated uranium fraction in an irradiated/natural uranium mixture has been described elsewhere. ${ }^{6,25}$

\section{Determination of oxidation state of uranium}

The method for determining the oxidation state of uranium is based on a soft carbonate leaching of hexavalent uranium (VI) without destruction of matrix $\mathrm{UO}_{2} .{ }^{26}$ As is well known, solubility of $\mathrm{UO}_{2}$ is negligible if oxidants are absent and it does not depend on $\mathrm{pH}$ value in a wide range from 2 to 12 . If fuel particles from nuclear fallout interact with the environment, the destruction rate of $\mathrm{UO}_{2}$ depends on several parameters including concentration of oxidants and complex-building reagents in the soil moisture, ambient temperature etc. The destruction can be described by a superposition of a slow weathering process of fuel particles with a reaction rate $R_{\text {slow }}=$ $0.005 \mathrm{mgU} \mathrm{m}^{-2} \mathrm{~d}^{-1}$ and a fast reaction of the oxidation of $\mathrm{U}(\mathrm{Iv})$ to $\mathrm{U}(\mathrm{vI})$ with $R_{\text {fast }}=0.19 \mathrm{mgU} \mathrm{m}^{-2} \mathrm{~d}^{-1}$. The latter reaction can be used to determine the degree of oxidation of fuel particles from the measured fraction of uranium leached by carbonate solution, i.e. fraction of $\mathrm{U}(\mathrm{vI})$. The total uranium concentration and uranium isotope ratios were measured by ICP-MS.

\section{Results and discussion}

The results of the study of the vertical distribution of natural and irradiated "Chernobyl" uranium in soil profiles are presented in Fig. 2-4. Measurements of natural uranium yielded significant variations of its concentration in upper soil layers from $2 \times 10^{-7} \mathrm{~g} \mathrm{~g}^{-1}$ to $3.4 \times 10^{-6} \mathrm{~g} \mathrm{~g}^{-1}$. Different pictures of natural uranium distribution (ascending, descending and combined) were observed even in similar soil types. For instance, in sandy soil samples collected in Pripyat 2 (Fig. 2a) the concentration of natural uranium was almost constant down to a soil depth of $30 \mathrm{~cm}$ and then increased in deeper soil layers (ascending distribution). In the peat profile collected in Chistogalovka (sampling point 1.2) a maximum natural uranium concentration was observed in the $10-20 \mathrm{~cm}$ soil layer. In deeper soil layers the descending character of uranium distribution was revealed. Relatively low uranium concentration in the upper peat layer can be explained by the low assimilability of uranium by partially decomposed residues of stems and leaves which represent a significant fraction in this layer. The third profile collected in Chistogalovka 1.1 represents a combined distribution of natural uranium.

This behavior of natural uranium can be explained by the well known conceptions of distribution and mobility of this element in the environment. ${ }^{27}$ In neutral and acid environment, $\mathrm{U}(\mathrm{vI})$ exists in the form of uranyl ions, which are inclined to build easily soluble complexes like $\left[\mathrm{UO}_{2}\left(\mathrm{CO}_{3}\right)_{3}\right]^{4-}$. In general, hexavalent uranium in the form of primary and complex ions

Table 1 Experimental parameters of ICP-MS

\begin{tabular}{|c|c|c|c|c|}
\hline \multirow{2}{*}{$\begin{array}{l}\text { ICP-MS type } \\
\text { Nebulizer }\end{array}$} & \multicolumn{2}{|l|}{ ICP-SFMS } & \multicolumn{2}{|l|}{ ICP-CC-MS } \\
\hline & Micromist $^{a}$ & Aridus $^{b}$ & Micromist $^{a}$ & Aridus $^{b}$ \\
\hline RF power/W & 830 & 1100 & 1350 & 1350 \\
\hline Cooling gas flow rate/ $\mathrm{min}^{-1}$ & 14.0 & 14.0 & 13.5 & 13.5 \\
\hline Auxiliary gas flow rate/l $\mathrm{min}^{-1}$ & 1.4 & 1.4 & 1.0 & 0.9 \\
\hline Nebulizer gas flow rate/l $\mathrm{min}^{-1}$ & 1.6 & 1.4 & 0.85 & 1.2 \\
\hline Solution uptake rate $/ \mathrm{ml} \mathrm{min}^{-1}$ & 0.2 & 0.1 & 0.3 & 0.1 \\
\hline Spray chamber temperature $/{ }^{\circ} \mathrm{C}$ & - & 70 & - & 70 \\
\hline Desolvator heating temperature $/{ }^{\circ} \mathrm{C}$ & - & 160 & - & 160 \\
\hline Sweep gas flow/l $\mathrm{min}^{-1}$ & - & 3.6 & - & 5.7 \\
\hline Extraction lens potential/V & 2000 & 2000 & 600 & 600 \\
\hline Hexapole exit lens/V & - & & 400 & 400 \\
\hline Hexapole bias potential/V & - & & 0.0 & 0.0 \\
\hline Ion energy lens/V & - & & 2.0 & 2.0 \\
\hline Multiplier voltage/V & & & 470 & 470 \\
\hline Mass resolution $(\mathrm{m} / \Delta m)$ & 300 & 300 & 300 & 300 \\
\hline
\end{tabular}




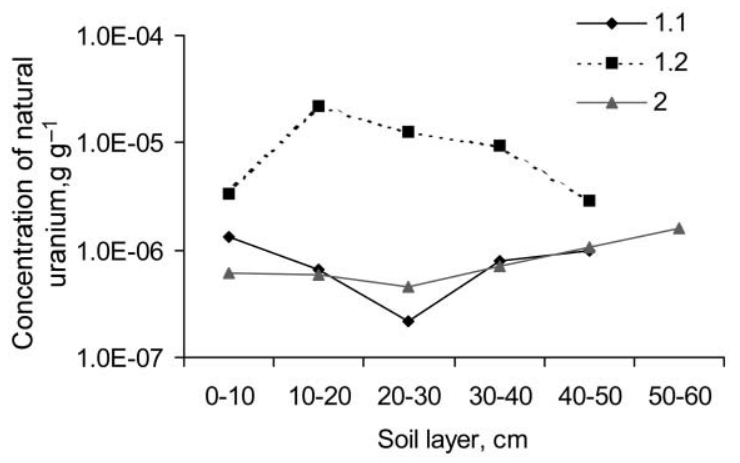

(a)

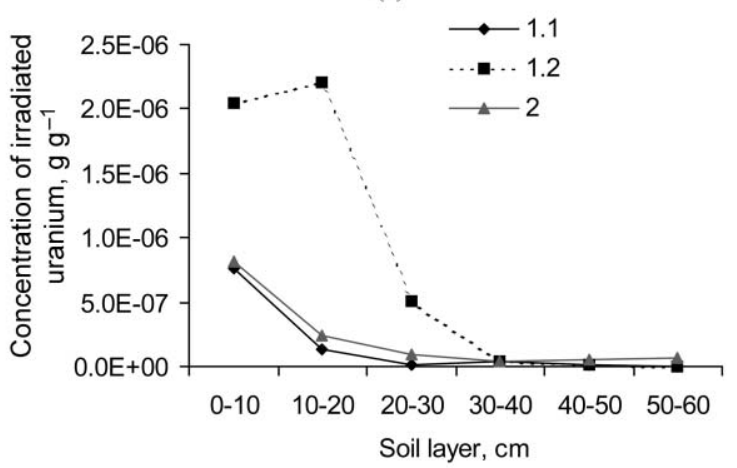

(b)

Fig. 2 Vertical distribution of (a) natural and (b) irradiated uranium in different soil types collected at sampling sites Chistogalovka 1.1 (turfpodzol), Chistogalovka 1.2 (peat) and Pripyat 2 (sand).

and especially in the form of carbonate complexes migrates vigorously. In contrast to U(vI) ions, U(Iv) ions are inclined to complex-building to a much lower extent. Tetravalent uranium has mostly low-soluble compounds, therefore its migration in the natural environment is limited. Vertical uranium distributions

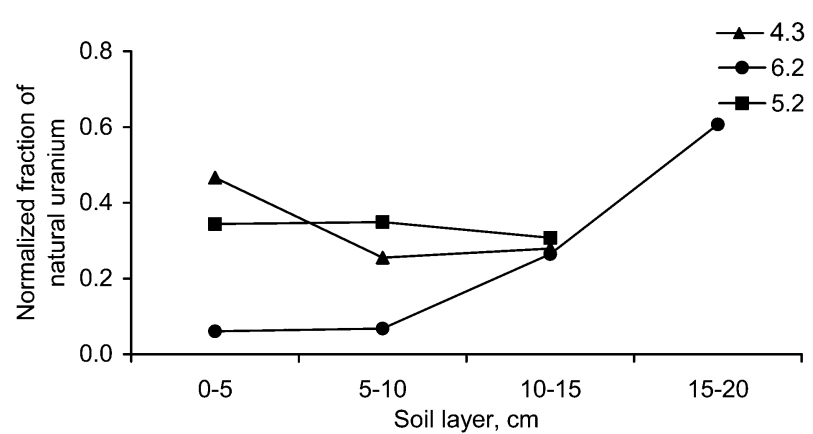

(a)

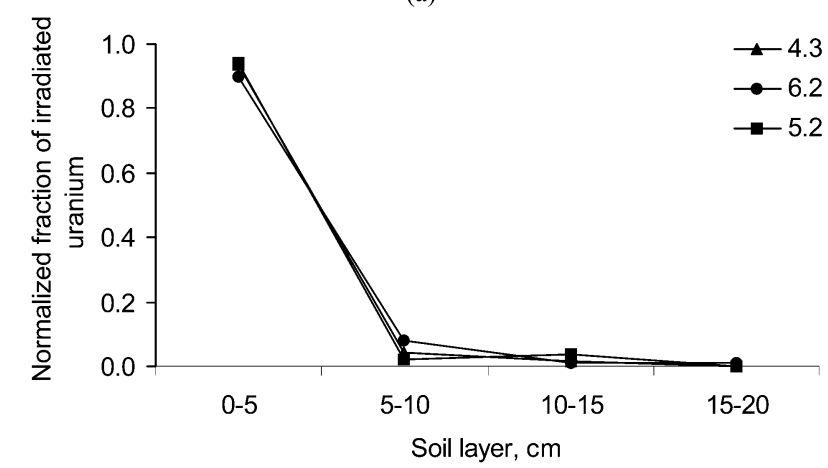

(b)

Fig. 3 Vertical distribution of (a) natural and (b) irradiated uranium in three peat profiles collected at sites Masany 4.3, Kulazhin 6.2 and Lesok 5.2 (amount of irradiated uranium in soil layers is normalized to the amount of irradiated uranium in the whole profile).

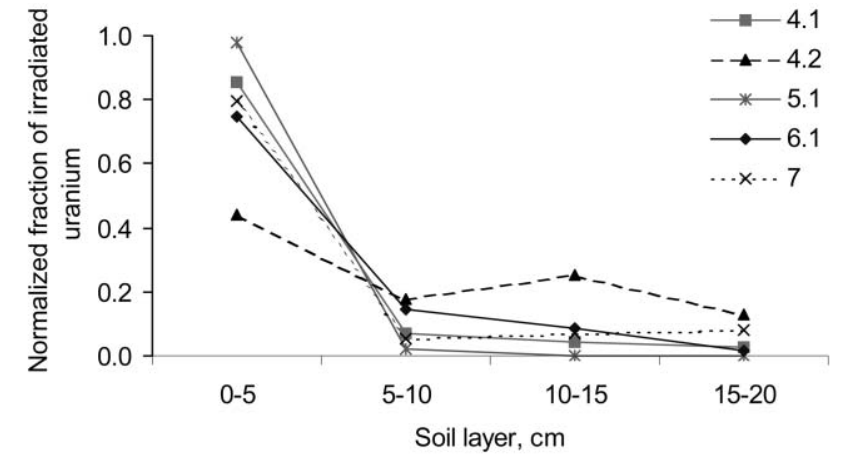

Fig. 4 Vertical distribution of irradiated uranium in turf-podzol soil profiles collected at sites Masany 4.1, Masany 4.2, Lesok 5.1, Kulazhin 6.1 and Hoiniki 7 (amount of irradiated uranium in soil layers is normalized to the amount of irradiated uranium in the whole profile).

measured in soils typical of Belarus (Fig. 2a and 3a) depend on the physico-chemical properties of soil and sources of uranium origin. The soils analyzed represent stagnant biosystems in which both ascending and descending types of mass transfer associated with the lithosphere, hydrosphere, atmosphere and biosphere take place. The type of soil-building rock, water regime and soil-building processes in different bioclimatic circumstances influence uranium concentration and distribution in soil. In general, uranium accumulation in different morphological horizons is determined by the oxidizing and restoring properties of soil depending on concentration of organic substances, calcium carbonate, as well as by mechanical properties of soil and by depth of occurrence of the soil-building rock. ${ }^{28}$

Another source of uranium access to soil is atmospheric aerosol formed for instance as a result of volcanic activity and secondary wind-driven resuspension (natural uranium), nuclear weapon tests (global fallout) ${ }^{29}$ or as a result of the Chernobyl NPP accident (local contamination with irradiated uranium). Surface contamination of soil with uranium from nuclear Chernobyl fallout takes place mainly in areas on Western and Northern radioactive traces in the $30 \mathrm{~km}$ zone of Chernobyl NPP. Concentrations of irradiated uranium in the upper $0-10 \mathrm{~cm}$ soil layers at the sampling sites investigated varied from $5 \times 10^{-12} \mathrm{~g} \mathrm{~g}^{-1}$ to $2 \times 10^{-6} \mathrm{~g} \mathrm{~g}^{-1}$ depending on the distance from Chernobyl NPP (Table 2). The highest concentrations of irradiated uranium were revealed in radioactive spots on Northern and Western radioactive traces located close to the Chernobyl NPP (Fig. 1). The distribution

Table 2 Soil types at sampling sites and measured concentration of irradiated uranium in upper $0-10 \mathrm{~cm}$ soil layer

\begin{tabular}{|c|c|c|c|}
\hline $\begin{array}{l}\text { Sampling } \\
\text { point }\end{array}$ & Name & Soil type & $\begin{array}{l}\text { Concentration of } \\
\text { irradiated uranium } \\
\text { in soil } / \mu \mathrm{g} \mathrm{g}^{-1}\end{array}$ \\
\hline 1.1 & Chistogalovka & $\begin{array}{l}\text { Turf-podzol, } \\
\text { sand-clay }\end{array}$ & 0.76 \\
\hline 1.2 & Chistogalovka & Peat & 2.0 \\
\hline 2 & Pripyat & Sand & 0.81 \\
\hline 3 & Hatki & $\begin{array}{l}\text { Turf-podzol, } \\
\text { sand }\end{array}$ & $2.1 \times 10^{-3}$ \\
\hline 4.1 & Masany & $\begin{array}{c}\text { Turf-podzol, } \\
\text { sand-clay }\end{array}$ & 0.78 \\
\hline 4.2 & Masany & $\begin{array}{l}\text { Turf-podzol, } \\
\text { sand-clay }\end{array}$ & $2.5 \times 10^{-2}$ \\
\hline 4.3 & Masany & Peat & 1.2 \\
\hline 5.1 & Lesok & $\begin{array}{l}\text { Turf-podzol, } \\
\text { sand }\end{array}$ & $2.5 \times 10^{-5}$ \\
\hline 5.2 & Lesok & Peat & $1.3 \times 10^{-4}$ \\
\hline 6.1 & Kulazhin & $\begin{array}{l}\text { Turf-podzol, } \\
\text { sand }\end{array}$ & $6.3 \times 10^{-3}$ \\
\hline 6.2 & Kulazhin & Peat & $4.6 \times 10^{-6}$ \\
\hline 7 & Hoiniki & $\begin{array}{c}\text { Turf-podzol, } \\
\text { sand-clay }\end{array}$ & $1.4 \times 10^{-5}$ \\
\hline
\end{tabular}


of irradiated uranium has a pronounced ascending character with $78 \%$ to $98 \%$ of irradiated uranium in the upper $0-10 \mathrm{~cm}$ soil layers in all profiles analyzed irrespective of the soil type. The migration of irradiated uranium to deeper soil layers was observed in sandy soil collected in Pripyat $2(62 \%$ in upper soil layer vs. $38 \%$ in $10-60 \mathrm{~cm}$ soil layer, see Fig. 2 b) and peat soil collected in Chistogalovka $1.2(39 \%$ in upper soil layer vs. $61 \%$ in $10-50 \mathrm{~cm}$ soil layer, see Fig. 2b). An almost identical distribution of irradiated uranium with more than $90 \%$ in upper $0-5 \mathrm{~cm}$ layer was observed in three peat profiles collected in Masany 4.3, Kulazhin 6.2 and Lesok 5.2 (Fig. 3b), in contrast to the distribution of natural uranium, which was homogeneous (Masany and Kulazhin) or even ascending (Lesok) in the profiles analyzed (Fig. 3a). In addition, Fig. 4 presents the distribution of irradiated uranium in five turfpodzol profiles, collected at different distances from Chernobyl NPP. In four profiles, $76 \%$ to $98 \%$ of irradiated uranium from Chernobyl fallout is still contained in $0-5 \mathrm{~cm}$ soil layers. Only one profile (Masany 4.2) has a less pronounced ascending character of irradiated uranium distribution. This sample was collected in a field where human activity shortly after the Chernobyl accident could not be excluded.

As was mentioned above, irradiated uranium released into the biosphere was initially in the nonsoluble U(Iv) oxidation state for which a slow migration in soils would be typical. Under the influence of active soil components uranium is leached and migrates faster. Results obtained on carbonate leaching of ${ }^{236} \mathrm{U}$ confirm that more than $60 \%$ of irradiated "Chernobyl" uranium still exists in a tetravalent form, i.e. is included in the fuel matrix (non-oxidized fuel $\mathrm{UO}_{2}$ ) (Table 3). No significant influence of $\mathrm{pH}$ value in soil solutions on the destruction rate of fuel particles was observed. It might not have been possible to detect this influence because the $\mathrm{pH}$ value varied only from 4.2 to 6.1 in the analyzed soil samples.

The destruction process of fuel particles can be described by the equation of the reaction kinetics: ${ }^{30}$

$$
A_{\tau} / A_{0}=\exp (-k \tau)
$$

$A_{\tau} / A_{0}$ is the fraction of tetravalent uranium in fuel particle at time $\tau ; k$ is the constant of the destruction rate of fuel particles $\left(\mathrm{yr}^{-1}\right)$.

The constants of the destruction rate of fuel particles were estimated taking into account experimental data obtained in the present study. The average value of the destruction rate of fuel particles obtained using carbonate leaching of ${ }^{236} \mathrm{U}$ was $k=0.030 \pm 0.005 \mathrm{yr}^{-1}$ for the Western radioactive trace and $k=0.035 \pm 0.009 \mathrm{yr}^{-1}$ for the Northern radioactive trace. Thus, the average values of the destruction rate coincide within experimental error for fuel particles both on Western and Northern radioactive traces despite the differences in the size distribution of radioactive particles. The results obtained confirm that primary fallout on both traces in the near vicinity of Chernobyl NPP (up to $30 \mathrm{~km}$ ) was represented by tetravalent uranium (non-oxidized fuel).

The earlier results ${ }^{2,30}$ on fuel particle destruction obtained by leaching ${ }^{90} \mathrm{Sr}$ differ significantly from the results of direct irradiated uranium leaching obtained in the present study. Thus, the destruction rate was $k=0.132 \pm 0.023 \mathrm{yr}^{-1}$ for the Western radioactive trace, but it varied from $0.007 \mathrm{yr}^{-1}$ to $0.085 \mathrm{yr}^{-1}$ in soils of the Northern radioactive trace, where fallout included the superposition of pure fuel and condensation component. However, the acetate leaching of strontium ${ }^{2,30}$ might be affected by considerable experimental errors when determining the destruction rate of fuel particles as it did not take into account the condensation fraction of ${ }^{90} \mathrm{Sr}$ and possibly irregular distribution of this radionuclide in fuel particles after burning (rim effect).

\section{Conclusions}

The main effect influencing the destruction rate of fuel particles is the degree of oxidation of the fuel matrix. Fuel fallout in both Western and Northern traces within the $30 \mathrm{~km}$ zone was represented by unoxidized fuel (tetravalent uranium), which has been only slightly transformed in the period since the accident. Slow oxidation under environmental conditions is confirmed by the low destruction rates of fuel particles. The latter was revealed by the measuring ratio of hexavalent uranium to tetravalent uranium extracted by carbonate leaching from fuel particles. The destruction rates of fuel particles in soils in different directions and at various distances from Chernobyl NPP within the $30 \mathrm{~km}$ zone coincide within experimental errors. The physical and chemical characteristics of soil do not significantly influence destruction processes of fuel particles. The measured values of the destruction rate obtained using ${ }^{236} U$ can be used for forecasting the radioecological situation in the Chernobyl area and estimating the transfer dynamics of radionuclides from the fuel matrix to mobile forms. Comparison of different methods of determining the destruction rate of fuel particles in soil using the leaching of fission products and uranium yielded poor coincidence. This is due to the fact that the use of fission products like ${ }^{90} \mathrm{Sr}$ to study fuel particle destruction did not take into account differences in the chemical properties of fission products and fuel matrix (uranium). The destruction rates obtained using fission fragments rather represented the degree of extraction of a particular element with a particular chemical reagent.

\section{Acknowledgements}

S.F.B. is grateful to the Alexander von Humboldt Foundation, Bonn, Germany for financial support for this work. The authors thank Dr. H.-J. Dietze for valuable discussions.

Table 3 Selective carbonate leaching of ${ }^{236} \mathrm{U}$ (vI) from different soil types on radioactive traces close to Chernobyl NPP

\begin{tabular}{|c|c|c|c|c|}
\hline Sampling point & Soil type & $\mathrm{pH}$ value of soil & $\begin{array}{l}\text { Concentration of } \\
\text { organic fraction }(\%)\end{array}$ & $\begin{array}{l}\text { Tetravalent fraction } \\
\text { of }{ }^{236} \mathrm{U}(\mathrm{vI})(\%)\end{array}$ \\
\hline \multicolumn{5}{|c|}{ Western radioactive trace } \\
\hline 1.2 & Peat & 6,0 & 68 & $75 \pm 2$ \\
\hline 1.1 & Turf-podzol, sand-clay & 4,5 & 9,2 & $64 \pm 4$ \\
\hline 3 & turf-podzol, sand & 5,0 & 1,2 & $70 \pm 6$ \\
\hline \multicolumn{5}{|c|}{ Northern radioactive trace } \\
\hline 7 & Turf-podzol, sand-clay & 6,1 & 2,1 & $67 \pm 6$ \\
\hline 4.1 & Turf-podzol, sand-clay & 5,0 & 1,3 & $68 \pm 10$ \\
\hline 4.2 & Turf-podzol, sand-clay & 4,2 & 8,9 & $68 \pm 12$ \\
\hline 6.1 & Turf-podzol, sand & 5,2 & 0,8 & $64 \pm 7$ \\
\hline 5.2 & Peat & 5,8 & 60 & $63 \pm 10$ \\
\hline
\end{tabular}




\section{References}

1 S. F. Boulyga, E. M. Lomonosova, I. V. Zhuk, O. I. Jaroshevich, V. P. Kudjashov and V. P. Mironov, Radiat. Meas., 1999, 30, 703.

2 V. Mironov, J. Matusevich and V. Kudrjashov, Destruction of fuel particles from the Chernobyl fallout on the territory of Belarus. In Radionuclides and Heavy Metals in Environment, ed. M. V. Frontasyeva, Kluwer Academic Publishers, The Netherlands, 2001, pp. 55-60

3 V. P. Mironov, L. E. Grushevich and V. P. Kudrjashov, Vestsi Akad. Navuk BSSR Ser. Fiz. Energ. Navuk, 1991, 4, 39.

4 G. Kirchner and C. Noack, Nucl. Safety, 1988, 29, 1.

5 S. N. Begichev, A. A. Borovoj, E. B. Burlakov, A. J. Gagarinsky, V. F. Demin, A. A. Khrulev and I. L. Khodakovsky, in Fission Product Transport Processes in Reactor Accidents, ed. J. T. Rogers, Hemisphere, New York, USA, 1990, p. 717.

6 S. F. Boulyga, J. L. Matusevich, V. P. Mironov, V. P. Kudrjashov, L. Halicz, I. Segal, J. A. McLean, A. Montaser and J. S. Becker, J. Anal. At. Spectrom., 2002, 17, 958.

7 V. Kudrjashov, V. Mironov and E. Konoplja, The contamination of Belarus territory by Transuranium elements. In Radionuclides and Heavy Metals in Environment, ed. M. V. Frontasyeva, Kluwer Academic Publishers, The Netherlands, 2001, pp. 127-134.

8 W. D. Davis and J. L. Mewherter, Geochim. Cosmochim. Acta, 1962, 26, 681

9 X.-L. Zhao, L. R. Kilius, A. E. Litherland and T. Beasley, Nucl. Instrum. Methods, 1997, B126, 297

10 X.-L. Zhao, M.-J. Nadeau, L. R. Kilius and A. E. Litherland, Nucl. Instrum. Methods, 1994, B92, 249.

11 D. Berkovits, H. Feldstein, S. Ghelberg, A. Hershkowitz, E. Navon and M. Paul, Nucl. Instrum. Methods, 2000, B172, 372.

12 S. Richter, A. Alonso, W. De Bolle, R. Wellum and P. D. P. Taylor, Int. J. Mass Spectrom., 1999, 193, 9.

13 A. M. Sanchez, F. V. Tome, J. D. Bejarano and M. J. Vargas, Nucl. Instrum. Methods, 1992, A313, 219.

14 J. S. Becker and H.-J. Dietze, Mass spectrometry of long-lived radionuclides. In Encyclopedia of Analytical Chemistry, ed. R. A. Meyers, John Wiley, Chichester, 2000, pp. 12947-12961.
15 S. F. Boulyga, J. S. Becker, J. L. Matusevitch and H.-J. Dietze, Int. J. Mass Spectrom., 2000, 203, 143.

16 S. F. Boulyga and J. S. Becker, Fresenius J. Anal. Chem., 2001, 370 612.

17 J. A. McLean, J. S. Becker, S. F. Boulyga, H.-J. Dietze and A. Montaser, Int. J. Mass Spectrom., 2001, 208, 193.

18 S. F. Boulyga, C. Testa, D. Desideri and J. S. Becker, J. Anal. At. Spectrom., 2001, 16, 1283.

19 V. P. Mironov, J. L. Matusevich and V. P. Kudrjashov, Method of uranium determination in soil and aerosol filters, Standard Method RB N MVI MH 1497, Belarussian State Committee for Standardization and Metrology, Minsk, 2001 (in Russian).

20 H.-J. Dietze, Ber. Zentralinstitut Isotopen Strahlenforschung Akad. Wissenschaften DDR, 1979, 27, 101.

21 P. D. P. Taylor, P. De Bievre, A. J. Walder and A. Entwistle, J. Anal. At. Spectrom., 1995, 10, 395.

22 K. G. Heumann, S. M. Gallus, G. Raedlinger and J. Vogt, J. Anal. At. Spectrom., 1998, 13, 1001.

23 W. Kerl, J. S. Becker and H. J. Dietze, Fresenius J. Anal. Chem., 1997, 359, 407.

24 EURACHEM/CITAC Guide, Quantifying Uncertainty in Analytical Measurement, ed. S. L. R. Ellison, M. Rosslein and A. Williams, Eurachem, London, 2nd edn., 2000, p. 120.

25 S. F. Boulyga and J. S. Becker, J. Anal. At. Spectrom., 2002, 17, 1143 .

26 V. P. Mironov, J. L. Matusevich and E. F. Konoplja, Method of determination of fuel particle destruction in environmental objects, Patent RB N A19980596, Minsk, 1998.

27 K. I. Lukashev, Geochemical provinces of cover deposits of BSSR, Nauka i Tehnika, Minsk, 1969, pp. 339-366.

28 Ecogeochemistry of the west Siberia. Heavy metals and radionuclear substances. Transaction of Russian Academy of Sciences Siberian Branch, Iss. 824, ed. G. V. Poljakov, Siberian Branch RAS SPC UIGGM, Novosibirsk, 1996, pp. 123-131.

29 V. A. Petrukhin, Monitoring of background contamination of environment, Nauka, Moscow, 1982, pp. 147-165.

30 J. L. Matusevich, Vestsi Natl. Akad. Navuk Belarusi Ser. Fiz. Energ. Navuk, 2001, 2, 140 